\title{
Research on the Collaborative Innovation Mechanism of the Automotive Industry Cluster Based on Original Collaboration
}

\author{
Xiujie Wang ${ }^{1,2, a} \quad$ Jian Liu $^{1, b^{*}}$ \\ ${ }^{1}$ College of Mechanical and Vehicle Engineering, Hunan University, Changsha, Hunan, 410082) \\ ${ }^{2}$ Guangxi University of Science and Technology, Liuzhou, Guangxi, 545006) \\ ${ }^{a}$ Xiujie_wang@sina.com, ${ }^{\mathrm{b}}$ liujian@hnu.edu.cn
}

Keywords: Original collaboration; Automobile Industry cluster; Innovation ecosystem; Innovation mechanism

\begin{abstract}
In this paper, based on the theory of industrial ecology, biological co evolution theory and automobile industry cluster innovation system characteristics, it is pointed out that automobile industry cluster innovation system is essentially an industrial ecosystem of mutual benefit and coexistence, co-evolution. The article has used Lojistic equation as a reference, which describing biology population growth law in biology, and established co evolution innovation mechanism mathematical model of innovation system in automobile industry cluster based on original collaboration, solved and analyzed the model. Based on the analysis results, this article puts forward some thinking and suggestions for the construction and development of innovation ecosystem of Chinese automobile industry cluster.
\end{abstract}

\section{Introduction}

Industrial ecology theory. When "industrial ecology" is used for expressing "industrial ecosystem", it refers to the composition pattern of industrial system, including various types, different scales, relationship between each other formed historically and unique cultural deposits of business and various kinds of organizations (Granovetter, 1994). Although these different entities are independent, through direct or indirect contact with each other, they build up a network (Harvey and Randles, 2002), forming a distinct complex cluster or company "ecology". Ind ustrial ecology deeply studies the interaction of various parts of the system, emphasizing integral analysis, and it is opposed to isolated research perspective, so systematized thinking becomes the core of industrial ecology[1].

Combination of industry and ecology is the demand of industrial development, it is also the logic extension of industrial economy research, and is more the realistic problem raised by environmental problems caused by industrial development[2]. Industrial ecology is based on the concept and principle of ecology, comprehensively uses methods and theories of multidiscipline, studies various industrial ecological phenomena and their causes, then grasps law of ind ustrial development, reveals development trend and direction of the industry, it is the reconstruction of industrial theory in ecological methods [3].

Industrial cluster is an effective way of space competition, it can realize scale economy in industrial level and is with strong cooperation innovation capability and advantages, increasingly becoming the center of innovation. At present, domestic and foreign scholars' analysis of 
technological innovation advantages of cluster tends to regard cluster as an environment plat supporting enterprise technology innovation, without considering the cluster as an organic ecosystem from the whole. If seeing with the latter perspective, it's not enough that to just pay attention to cluster enterprise's spontaneous innovation with individual characteristic, and need to inspect the orderly integration of innovation, i.e. cluster members' technical innovation activities and results coordinating mutually to meet cluster's requirements for innovation as an organic system[4]. Industrial ecosystem essentially gets development potential by the mutual collaboration of human behavior with geographical proximity in organization interface. The synergy of ind ustrial ecosystem enhances the efficiency and the benefit of use of the system resources[5] .

The relevancy degree of automotive industry is high, industrial chain is long, its reliance and driving on related industries are strong, by implementing collaborative innovation of industrial cluster, we can effectively promote the rapid and stable development of automobile industry and reduce risk. At present, automobile enterprises in most countries of the world improve competitiveness and accelerate development by way of industrial cluster, such as Japan's Toyota City, United States' Detroit Motor City, Stuttgart of Germany. Automobile industry cluster innovation system not only needs to analyze what's the structure and role of various parts of system and mutual interdependence within system, it also need to identify what kind of resource competing mechanism and logical relationship seriously impact the entire system, i.e., from the perspective of the whole ecosystem to seek innovation power in cluster.

Original collaboration co evolution theory. Co evolution is an important theory in evolutionary biology, it originally derived from the study of the relationship between butterflies and plants by Enrique (P.H.Ehrlich) and Levine (P.Raven). Janzen (D.H.Janzen) gave the definition of co evolution in 1980: a certain characteristic of a species evolves by reacting on a certain characteristic of another species, the characteristic of the lateral so evolves in response to the characteristics of the former. Recent studies have found that co evolution not only exists among population (or species), it also exists among population (or species) and environment. The co evolution between nature species has four forms, predation competition, non-predation competition, original collaboration and mutualism. The original collaboration refers to that two species interact, which are beneficial to both sides, but both sides can still live independently after they separate from each other. Mutualism manifests is beneficial to both sides, but it has developed to the extent that both sides cannot leave each other to live independently, it belongs to obligate symbiosis.

The significance of co evolution is mainly reflected in the value of "synergy", and the result is more favorable for biological evolution. The biology coexisting phenomena in natural communities shows that populations surviving in certain natural environment resource constraints impel each other to improve their own performance and complexity by competition and collaboration between them, enabling co evolution between populations. The collaboration between biology and collaboration between biology and environment are both an interaction process between biology and function act of biology. The collaboration and competition between biology are complementary, which can transform into each other under certain conditions, the competition result may be "survival of the fittest, species extinction", or may adapt to each other and co evolution to reach relative stability of communities and ecosystem[6].

Automotive industry cluster belongs to collaborative cluster that gathered by enterprises proceeding specialization cooperation in the fields of materials and components. In the process of innovation organizations in automobile industry cluster fighting for innovation resources, strictly 
speaking, the competition between them does not belong to the prey relationship of "you die and I die", and it is the general non-predatory competition. In addition, although in domestic and international automotive industry group, it is common that there is a relatively tight supporting partnership between upstream businesses and downstream businesses, but strictly speaking, it does not belong to the absolute interdependence between populations in ecology, so mutualism co evolution form does not exist in automotive cluster innovation ecosystem, but mainly two modes of original collaboration and non-predatory competition exist. Among them, in the early and mid-term of automotive industry cluster development, the former is dominated in innovation ecosystem, ,the latter dominated in later period. Currently, most of China's automobile industry clusters belong to early and mid-term development, so this paper mainly analyzes innovation mechanism of automotive cluster innovation ecosystem based on the original collaboration.

\section{Automobile industry cluster innovation ecosystem}

Automobile industry cluster constant innovation ecosystem is referred to that, in a geographical location, taking a leading industry as center, with largely contact closely-linked innovation organizations and relevant support environmental elements to gather in particular space, through various interactions, it is continuously promoted that technological innovation, knowledge innovation, organizational innovation and institutional innovation, forming an adjustable innovation network system with self-organization. Automobile industry innovation ecosystem is mainly made up of innovation body, innovation supporting institutions (suppliers of innovation factors) and innovation environment of three parts, the essence is an interaction innovation ecosystem network system, which can create, reserve and transfer the knowledge, skills and new product.

\section{Co evolution innovation mechanism under the original collaboration model}

Single population growth Logistic model. Based on the Logistic classical model predicting single population growth in modern ecology, this paper builds innovation mechanism and organizational innovation mechanism model in automobile industry cluster[7]. In automobile industry cluster innovation ecosystem with limited innovation resources, development of any innovative organizational structure will be subject to the constraints of scarce innovation resources(such as capital, technology, market, etc.), it will always achieve the "saturation level" of growth, i.e. growth limits, and its growth limits depend on the scarce innovation resources in system. Therefore, in automotive industry cluster innovation ecosystem, innovative growth of single innovation population follows the Logistic law:

$$
\frac{\mathrm{dN}}{\mathrm{dt}}=\mathrm{rN}\left(1-\frac{\mathrm{N}}{\mathrm{K}}\right)
$$

Where: $\mathrm{N}$ is the innovation output value of a single innovation organization in cluster at time $\mathrm{t}, \mathrm{r}$ is inherent growth rate of innovation organization innovation output, and the intrinsic increase rate of corporate eco-efficiency, is related with the inherent characteristics of the industry itself, and it can be considered as a constant in innovation ecosystem's dynamic running in automobile industry cluster; $\mathrm{K}$ is the maximum innovation organization innovation output that could achieved in the case

that its resources can be fully used; $\left(1-\frac{N}{K}\right)$ is Logistic coefficient, it has a braking effect on 
innovation output changes of innovation institutions, so that quantity of populations always tends to meet environmental capacity.

Model's construction and solving. Under the original collaboration model, because organization $\mathrm{n} 2$ and organization $\mathrm{n} 1$ promote mutually in terms of innovation capacity growth, we can build $\mathrm{n} 1$ and $\mathrm{n} 2$ innovation capacity growth model under the original collaboration competition model based on formula 1[8]:

$$
\left\{\begin{array}{l}
\frac{\mathrm{dN}_{1}}{\mathrm{dt}}=\mathrm{r}_{1} \mathrm{~N}_{1}\left(1-\frac{\mathrm{N}_{1}}{\mathrm{~K}_{1}}+\alpha \frac{\mathrm{N}_{2}}{\mathrm{~K}_{1}}\right)=\mathrm{f}\left(\mathrm{N}_{1}, \mathrm{~N}_{2}\right) \\
\frac{\mathrm{dN}_{2}}{\mathrm{dt}}=\mathrm{r}_{2} \mathrm{~N}_{2}\left(1-\frac{\mathrm{N}_{2}}{\mathrm{~K}_{2}}+\beta \frac{\mathrm{N}_{1}}{\mathrm{~K}_{2}}\right)=g\left(\mathrm{~N}_{1}, \mathrm{~N}_{2}\right)
\end{array}\right.
$$

To make $f\left(N_{1}, N_{2}\right)=0$ and $g\left(N_{1}, N_{2}\right)=0, P 4\left(\left[\frac{(1+\alpha)}{1-\alpha \beta} K_{1}, \frac{(1+\beta)}{1-\alpha \beta} K_{2}\right]\right.$ is got, which is the stable equilibrium point of innovation benefits under the original collaboration model.

Model analysis. (1) When both $\alpha=0$ and $\beta=0$, the innovation resource utilization of organization $\mathrm{n} 1$ and organization $\mathrm{n} 2$ is unrelated, each of them follows Logisitc law to grow and eventually reaches their equilibrium state N1, N2. In this case, such organizations within cluster show only geographically close to each other, no synergy produced during this procedure. Moreover, because these organizations compete for innovation resources and location advantages, the innovation capacity of the entire automobile industry cluster system is reduced instead. Automobile industry cluster is not just a simple gathering of a large number of enterprises, more importantly, it is close cooperation relationship formed among these enterprises in order to play collaborative innovation advantages of enterprises within cluster. Therefore, we should strictly formulate preentering and post-entering evaluation criteria of automobile park and strive to build resultant force of cluster innovation and development.

(2) When $\alpha<1 、 \beta<1$ and $\alpha \beta<1$, there is a certain mutual cooperation between $\mathrm{n} 1$ and $\mathrm{n} 2$, but not close. In the condition that technological development level constantly improving, the cooperation space betweenn1 and $\mathrm{n} 2$ will continue to expand. At this time, there are innovation cooperation need and potential in automobile cluster, but limited to enterprises' own conditions, then the government should studies economic behavior and environmental behavior of enterprises, formulates and implements preferential taxation, economic subsidies, preferential procurement and other policies, to drive ecology enterprises to actively participate in cooperation between ente rprises with economic interests.

(3) When $\alpha<1 、 \beta>1$ and $\alpha \beta<1$, this represents $\mathrm{n} 2$ is core enterprise, $\mathrm{n} 1$ is satellite enterprise, indicating $\mathrm{n} 2$ leads innovation for $\mathrm{n} 1$, and $\mathrm{n} 2$ has greater impact on $\mathrm{n} 1$; Conversely, $\mathrm{n} 1$ has small contribution to the building of innovation capacity of $\mathrm{n} 2$. Therefore, when the government formulates development plan and related policies of automobile industry cluster, which should be increased that the support efforts for automobile factory and key parts enterprises to promote the rapid development of core businesses, which can promote the development of the surrounding satellite type small parts enterprises and medium parts enterprises, thus improving the innovative capacity of the entire cluster. When $\alpha>1, \beta_{<1}$ and $\alpha \beta<1$, the situation is just the opposite. 


\section{Conclusions}

In natural ecosystems, cooperative development promotes mutual interdependence and coord ination. In automobile industry cluster innovation system, different innovation bodies cooperate with each other to advance, optimize their innovation advantages and to enhance the industry's core competitiveness. Ecology provides a new approach and perspective for automotive industry cluster innovation research. The article uses Lojistic equation of population growth in biology for reference, builds co evolution mechanism mathematical model in automobile cluster innovation ecosystem based on the original collaboration, and ccording to analysis results, this article puts forward some thinking and suggestions for innovation construction and cluster development in Chinese automobile industry cluster.

Fund: Subsidized by Hunan soft science key project "Research on Hunan automobile industry development technical chain and innovation system construction" issue(project number: 2014zk2050)

Author: Wang Xiujie(1977-), female, Tianjin Ninghe, doctoral candidate, associate professor, research direction is automotive industry development.

Liu Jian ( Corresponding author), male, born in 1975, doctor, professor, doctoral tutor. The main research directions are industrial engineering, and automotive industry development.

\section{References}

[1] Grinnel. J. Geography and Evolution[J]. Ecology,1924,(05):225-229.

[2] R A Frosch, N E Gallopoulos. Towards An Industrial Ecology in The Treatment and Hand ling of Wastes[M]. London: Chapman and Hall, 1992.262-292.

[3] Jonah S. Beyond the food web: connections to a deeper industrial ecology[J]. Journal of Industrial Ecology, 2002,6(1).

[4] Shang Changyu. General Ecology [M] Beijing: Peking University Press, 2002.101-120.

[5]Huang Lucheng.Regional technical innovation system research: Reflections on ecology [J] Science Studies, 2003, 21 (4): 215-219

[6] Liu Youjin.Behavioral ecology of enterprise technological innovation cluster behavior -propose and thinkingof an analytic framework [J] China Soft Science, 2004, (1): 68-72

[7] CaoXianbin.Coevolutionbased on ecological species competition model [J] SoftwareJournal, 20001,12, (04): 556 - 562.

[8] Zhang Jintun.Quantitative ecology [M] Beijing: Science Press, 2004.60-90. 